\title{
Sentidos argumentativos e polifônicos de números, no discurso, com base na Semântica Argumentativa ${ }^{1}$
}

\author{
Argumentative and polyphonic meanings of numbers, within discourse, \\ based on Argumentative Semantics \\ Lauro Gomes \\ Universidade de Passo Fundo - Passo Fundo - Rio Grande do Sul - Brasil \\ Norton Pizzi Manassi \\ Noemi Luciane dos Santos \\ Instituto Federal de Educação, Ciência e Tecnologia do Rio Grande do Sul - Erechim - Rio Grande do Sul - Brasil
}

$\diamond$

Resumo: Com base na Semântica Argumentativa, proposta por Oswald Ducrot e colaboradores, este trabalho propõe-se a examinar e a explicitar a relação semântico-argumentativa existente entre linguagens verbal e numérica no discurso. Para tanto, realiza-se uma análise argumentativa e polifônica de um discurso, cujos números nele empregados ganham a função própria de signo linguístico, constituem enunciados e notadamente argumentam. Desse modo, este artigo vai ao encontro de trabalhos desenvolvidos na área de educação matemática, como o de Ole Skovsmose (2013), em que o autor defende que a matemática serve de suporte para argumentações e debates ligados a questões sociais e, portanto, torna-se parte de uma linguagem que influencia na tomada de importantes decisões na sociedade contemporânea. Pretende-se, pois, introduzir uma discussão teórico-aplicada e interdisciplinar, que, além de permitir o avanço das ciências linguística e matemática, poderá fornecer ferramentas de leitura a serem utilizadas no ensino de língua e no de ciências exatas.

Palavras-chave: Argumentação linguística; Linguagem numérica; Discurso; Ensino

\begin{abstract}
Based on Argumentative Semantics, proposed by Oswald Ducrot and collaborators, this paper aims to examine and to explain the argumentative and semantic relation existing between verbal and numerical language within discourse. Therefore, it is carried an argumentative and polyphonic analysis of one discourse, whose numbers used in it gain the function of the linguistic sign itself, constitute utterances and clearly make argumentations. That way, this paper meets works done within the area of mathematics education, as the work of Ole Skovsmose (2013), in which the author defends that mathematics serve as support for argumentations and debates related to social issues and thus it becomes part of a language that influences the effectuation of important decisions in nowadays society. It is intended, therefore, to introduce a theoretical, applied and interdisciplinary discussion, which, besides allowing the advancement of linguistic and mathematical sciences, can provide reading tools to be used in language teaching and inexact sciences teaching.
\end{abstract}

Keywords: Linguistic argumentation; Numerical language; Discourse; Teaching

1 Este trabalho foi apresentado - na modalidade comunicações - no V Seminário Nacional de Linguística e Ensino de Língua Portuguesa (V SENALLP), realizado de 02 a 04 de setembro de 2015 na Universidade Federal do Rio Grande (FURG). 


\section{Introdução}

Este trabalho propõe-se a examinar os sentidos argumentativos e polifônicos de números no discurso tema que constitui interesse tanto à linguística quanto à educação matemática. Contudo - mesmo se reconhecendo a relevância e a necessidade de se trabalhar, sobretudo no ensino, com a força argumentativa da linguagem numérica em discursos - ainda são escassos os trabalhos que buscam explicitar a semântica de números e, notadamente inexistentes as pesquisas que a estudam por vias enunciativo-discursivas e interdisciplinares.

De antemão, o próprio tema deste trabalho pode gerar certo estranhamento por estar-se propondo a investigar os efeitos produzidos por um sistema de signos de natureza objetiva (numérico) que - quando colocado em funcionamento dentro do principal sistema de signos (língua) - constitui sentido e também argumenta. Esse fenômeno, ainda pouco explorado em linguística, filia-se indubitavelmente ao pensamento saussuriano a respeito da linguagem. No Curso de Linguística Geral (1916), Saussure já esclarecera que a linguagem tem um lado individual (fala) e um lado social (língua) e afirmara ser impossível conceber um sem o outro.

Sequencialmente, é interessante observar que - ao postular que a língua é um sistema gramatical e virtual depositado pela prática da fala incompletamente nos cérebros de todos os indivíduos pertencentes à mesma comunidade - Saussure (1975, p. 24) também destacou que "a língua é um sistema de signos que exprimem idéias, e é comparável, por isso, à escrita do alfabeto dos surdos-mudos, aos ritos simbólicos, às formas de polidez, aos sinais militares etc., etc. Ela é apenas o principal dêsses sistemas". Eis, portanto, que o sistema linguístico pode ser comparado ao sistema numérico, dentro do qual este também atua.

A tradição dos estudos gramaticais (BECHARA, 2009 , p. 203) chama numeral à classe de palavra responsável por quantificar, denotar valor definido, entendendo os numerais cardinais (um, dois, três, etc) como os propriamente ditos. No entanto, a tradição gramatical, segundo o referido autor, tem incluído entre esses numerais próprios também os seguintes: os ordinais (primeiro, segundo, terceiro, etc), os multiplicativos (dobro, triplo, quádruplo, etc) e os fracionários (meio, terço, quarto, etc). Confiram-se, ainda, palavras de Mattoso Câmara:

A relação entre os nomes numerais da língua e a arte de contar condiciona, na língua escrita, o uso de números em vez de palavras correspondentes; ex.: 24 de agosto, 3 horas, 12 anos, rua X 23, capítulo 32. Assim os numerais passam a ser indicados na língua escrita por ideogramas. (CÂMARA JR., 1978, p. 178).
Isso tudo comprova que, como as palavras, os números também estão na língua, naquilo que Saussure chamou de tesouro depositado no cérebro de cada indivíduo. Por isso, quando os números são postos em funcionamento pelo sistema linguístico, devem ser examinados, relativamente à constituição de sentidos no discurso, com o mesmo cuidado com que se investigam as palavras - ou quiçá com ainda mais rigor, devido à credibilidade que as sociedades ocidentais têm dado, ao longo dos tempos, à matemática.

No ensino de língua, mais especificamente a propósito do ensino de argumentação e de produção de textos dissertativos, é comum os livros didáticos apresentarem os chamados argumentos baseados em provas concretas, em que normalmente se citam dados estatísticos, a fim de corroborar a defesa de uma tese. Em geral, seguem-se, nesses livros, recomendações aos estudantes em relação à qualidade dos dados. Savioli e Fiorin (1999), por exemplo, recomendam que "os dados apresentados devem ser pertinentes, suficientes, adequados, fidedignos". O que falta são estudos que visem a desvelar os sentidos duvidosos e falsos, até, que os números constroem em discursos - a cujo objetivo específico propõe-se este trabalho.

Em vista disso - para que fosse possível atingir os propósitos deste estudo - elegeu-se a teoria da Argumentação na Língua ( $\mathrm{ADL}^{2}$, daqui em diante), proposta por Anscombre e Ducrot (1983), especialmente na sua versão recente, a Teoria dos Blocos Semânticos (TBS, daqui em diante), proposta por Carel (1992), uma vez que, filiada a Saussure, essa teoria defende a tese de que a argumentação está na língua e que argumentar consiste em evocar das entidades linguísticas (palavra, enunciado e discurso) encadeamentos argumentativos em portanto (donc), ditos normativos, e em mesmo assim (pourtant), ditos transgressivos.

No sentido de discorrer sobre a ADL, dentro dos limites deste trabalho, apresentam-se, a seguir, os seus fundamentos filosóficos, acrescidos de conceitos da fase Standard $^{3}$ e da TBS, essenciais aos propósitos deste estudo. Posteriormente, discute-se sobre a ideologia da certeza na educação matemática, para que se possa explicitar, por fim, a necessidade que a matemática deve cada vez mais apresentar de também ensinar a ler o mundo. Na sequência do trabalho, analisa-se um discurso, no qual linguagens verbal e numérica se relacionam, e em que esta constitui encadeamentos argumentativos e

\footnotetext{
2 ADL é a abreviatura do nome da teoria linguística francesa "l'Argumentation Dans la Langue".

3 A título de esclarecimento, a fase Standard é a primeira fase de desenvolvimento da ADL; a Standard Ampliada - que compreende a Teoria Polifônica da Enunciação e a Teoria dos Topoi - é a segunda fase da ADL, e a Teoria dos Blocos Semânticos é a terceira e atual fase da ADL.
} 
também argumenta. Finalmente, apresenta-se a conclusão com os resultados obtidos na análise.

\section{Conhecendo a teoria da argumentação na língua}

\subsection{Em que se fundamenta a Semântica Argumentativa?}

A teoria da Argumentação na Língua ("l'Argumentation Dans la Langue"), também chamada de Semântica Argumentativa, foi criada em 1983, na França, por Oswald Ducrot e Jean-Claude Anscombre, e é atualmente continuada por Ducrot com a colaboração de Marion Carel. Para que se possa encontrar uma resposta à questão levantada já no título desta subseção, é preciso retornar à origem filosófica da teoria - fundamentalmente, à noção de alteridade apresentada por Platão em $O$ sofista; e às noções de valor linguístico e de relação, tal como propostas por Ferdinand de Saussure no CLG ${ }^{4}$.

Tanto no citado "Prefácio" para o livro O Intervalo Semântico, de autoria de Carlos Vogt (2009), quanto no capítulo do livro Nouveaux regards sur Saussure (2006) - intitulado La sémantique argumentative peutelle se réclamer de Saussure? - Ducrot deixa claro que a noção saussuriana de valor sempre esteve no centro de seus trabalhos em semântica. No referido texto de 2009 , Ducrot, profundo conhecedor da filosofia clássica, viu a noção saussuriana de valor sendo fundamentada pela alteridade platoniana. Explica Ducrot que, ao tratar das categorias fundamentais da realidade - o Movimento, o Repouso, o Mesmo e o Ser - Platão acrescenta uma quinta categoria - o Outro -, colocando-a como o fundamento de todas as outras. Ou seja, cada categoria somente é o que é porque é Outro. E, para Saussure, o valor linguístico decorre da relação que um signo estabelece com os outros signos.

Isso significa que a Semântica Argumentativa assume como sua fundamentação filosófica a noção de alteridade de Platão, trazida para o estudo da linguagem por Saussure. Seguindo o viés saussuriano claramente apresentado na "Nota sobre o discurso" - um dos manuscritos que compõem a obra Escritos de Linguístia Geral - de que a língua só é criada em vista do discurso, segundo esclarece Barbisan (2013, p. 20): "Ducrot leva a noção de valor linguístico para o emprego da língua, mostrando-o em diferentes níveis: na relação entre entidades lexicais, entre enunciados, entre discursos, entre locutor e alocutário".

Eis que - conforme afirma Ducrot (2009, p. 11) - "a língua é, antes de mais nada, o lugar da intersubjetividade, o lugar onde os indivíduos se confrontam, o lugar onde encontro outrem". Desse modo, o valor argumentativo, nível fundamental da descrição semântica, pode ser entendido, nas palavras de Ducrot (1990, p. 51), como a orientação que a palavra dá ao discurso. Decorre, essa orientação argumentativa, da significação, a qual consiste em um conjunto de instruções, de diretivas que permitem interpretar os enunciados da frase $e^{5}$. Nessa relação linguisticamente estabelecida, locutor e alocutário se confrontam; e, portanto, argumentar é, para a ADL, levar o Outro a determinada continuação do discurso e não a outra.

A título de esclarecimento, Ducrot (1990, p. 61) explicita que, se em determinada situação alguém perguntar o preço de determinado objeto e contestarse dizendo (1) Ele custa 100 francos e talvez até 150. (Il coûte 100 francs et peut-être même 150), vai-se mostrar ao interlocutor que o objeto é caro e difícil de comprar. Se, contudo, responder-se (2) Ele custa 150 francos e talvez até 100. (Il coûte 150 francs et peut-être même 100), vai-se mostrar ao interlocutor, ao contrário de (1), que o objeto é barato e que é fácil de comprá-lo.

Na mesma conferência de Polifonia y Argumentación, em que apresenta esses exemplos, Ducrot (1990, p. 79) esclarece a diferença entre as expressões "mais de" e "menos de". Afirma que esta conduz a uma avaliação de preço orientada para "barato" e que aquela conduz a uma avaliação orientada para "caro". Dessa maneira, supondose que determinado objeto custe 12 francos, pode-se dizer "custa mais de 10 francos" ou "custa menos de 15 francos". Mesmo sendo os dois enunciados igualmente verdadeiros - servindo para expressar um valor ligeiramente superior a 10 - a continuação argumentativa neles autorizada é completamente diferente. Nesse contexto linguístico, a responsabilidade é do locutor de conduzir o seu alocutário a continuar o enunciado com "é barato" ou com "é caro".

A partir disso, Ducrot explicita o fato semiológico de se apresentar, nas vitrines das lojas, o preço 999 francos, mas quase nunca 1.001. Leia-se:

A explicação é que quando vemos 999 entendemos em seguida que se trata de um valor inferior a 1.000 e por conseguinte concluímos que o objeto é barato. Ao contrário, quando lemos 1.001 pensamos sempre no enunciado "mais de 1.000 " e neste caso se chega à conclusão de que o objeto é caro. (DUCROT, 1990, p. 79, tradução nossa) ${ }^{6}$.

\footnotetext{
4 Abreviatura de Curso de Linguística Geral (Cours de Linguistique Générale).

5 De acordo com Ducrot (1990, p. 53), enquanto a frase é uma entidade linguística abstrata - que serve para explicar a infinidade de enunciados - o enunciado é uma entidade empírica, uma das múltiplas realizações possíveis de uma frase. Em decorrência disso, uma sequência de frases constitui um texto, e uma sequência de enunciados constitui um discurso.

6 La explicación es que cuando vemos 999 entendemos en seguida que se trata de un valor inferior a 1.000 y por consiguiente concluimos que el objeto es barato. En cambio, cuando leemos 1.001 pensamos siempre en el enunciado "más de 1.000" y en este caso se llega a la conclusión de que el objeto es caro.
} 
A natureza semiológica das expressões mais e menos tem, segundo Ducrot, uma influência sobre a expressão semiológica e até não linguística, uma vez que, quando se lê a informação aritmética 999, imediatamente se pode traduzi-la ao enunciado linguístico "menos de 1.000 " e é esse enunciado subjacente o que permite entender o valor argumentativo de 999.

Nesse confronto instalado entre locutor e alocutário em cada enunciado, imprimem-se, linguisticamente, subjetividade e intersubjetividade. Por conseguinte, a Semântica Argumentativa rejeita a existência de um aspecto objetivo na linguagem e defende - não que a língua impõe uma ideologia - mas que deixa uma certa liberdade ideológica e que funciona graças à ideologia contida na sociedade. Daí decorre a conhecida afirmação de Ducrot (1990, p. 151) de que a língua necessita da ideologia.

Em vista disso, os objetivos deste trabalho estão em consonância com essa concepção argumentativa de linguagem, visto que buscam investigar a relação semântico-argumentatica entre as linguagens verbal e numérica - mais especificamente os sentidos argumentativos e polifônicos de números no discurso - muitos dos quais podem ser facilmente explicitados, quando se passa a assumir a existência de uma ideologia colocando em funcionamento também o sistema numérico nos discursos, em sociedade.

\subsection{Princípios e conceitos da Teoria dos Blocos Semânticos}

A Teoria dos Blocos Semânticos (TBS) - postulada com a tese de doutorado de Marion Carel, sob o título "Vers une formalisation de la théorie de l'Argumentation Dans la Langue" (1992) - é atualmente desenvolvida por Ducrot e Carel na Escola de Altos Estudos em Ciências Sociais de Paris. Como já afirmado inicialmente, a TBS é considerada a forma atual da ADL, e essa afirmação se justifica na medida em que rejeita as noções de topos e de forma tópica, da Teoria dos Topoi, opondo-se à ideia de passagem de um argumento (A) para uma conclusão (C) - noção ainda muito vinculada ao logicismo aristotélico.

Nessa fase de desenvolvimento da teoria, Carel deu-se conta de que, com a introdução do topos, um princípio extralinguístico, estavam-se traindo os próprios fundamentos da ADL, de estudar a língua a partir dela mesma, e inclusive a sua tese de que a argumentação está na língua. Retornando, portanto, aos fundamentos saussurianos fundadores da ADL, Carel postulou que o sentido das entidades linguísticas - palavra, enunciado e discurso - surge da interdependência semântica que se estabelece entre dois predicados que, unidos por meio de portanto $($ donc $=\mathrm{DC})$ ou de mesmo assim (pourtant $=$ PT), expressam um bloco semântico.
Isso significa assumir a tese de que o sentido originase sempre numa relação de dois predicados, isto é, no que se convencionou chamar encadeamento argumentativo, existente sob a fórmula X CONECTOR Y. Ou seja, um predicado como Diriges depressa demais nada significa, até que não se possa dar-lhe continuações, como corres o risco de cometer um acidente, ou corres o risco de cometer uma infração. Note-se que, no encadeamento argumentativo (1) Diriges depressa demais, corres o risco de cometer um acidente, relaciona-se a entidade semântica unitária e indecomponível (bloco semântico) segundo a qual pode acidentar-se quem anda em alta velocidade; e, no encadeamento argumentativo (2) Diriges depressa demais, corres o risco de cometer uma infração, relacionase o bloco semântico segundo o qual pode cometer uma infração quem anda em alta velocidade.

Diante disso, verifica-se que o conteúdo do predicado $X$ somente pode ser compreendido pela relação que estabelece com o conteúdo do predicado $Y$. Sendo assim, o sentido literal, informacional das palavras da língua torna-se totalmente desnecessário para a compreensão dos enunciados. Cada encadeamento argumentativo dá uma apreensão argumentativa da realidade. E, relativamente ao sentido de velocidade expresso nos referidos encadeamentos argumentativos (1) e (2), pode-se perceber que ele não é o mesmo.

De modo geral, segundo esclarecem Carel e Ducrot (2005), se um predicado contém, em sua significação, a possibilidade de que lhe seja encadeado portanto $Y$ (X DC $\mathrm{Y})$, ele contém também a possibilidade de que lhe seja encadeado mesmo assim não $Y$ (X PT NEG-Y). Assim, podendo-se encadear Diriges depressa demais a portanto corres o risco de cometer um acidente (encadeamento normativo), também se pode encadear Diriges depressa demais a mesmo assim não corres o risco de cometer um acidente (encadeamento transgressivo), ficando vetada ao menos na linguagem cotidiana - a possibilidade de se encadear *Diriges depressa demais a portanto não corres o risco de cometer um acidente, por exemplo, que é um encadeamento argumentativo paradoxal. Segundo os referidos autores, são esses - normativos e transgressivos - os dois únicos tipos de encadeamentos argumentativos, também chamados de unidades semânticas básicas.

De acordo com Carel e Ducrot (2005, p. 20), a TBS também propõe chamar aspecto argumentativo a um conjunto de encadeamentos argumentativos. Desse modo, uma concatenação do tipo A DC B chamase de aspecto, visto que representa um conjunto de encadeamentos argumentativos normativos X DC Y. Um aspecto como PERTO DC FÁCIL CHEGAR contém, entre outros, encadeamentos como (1) O hotel está perto da universidade, portanto é fácil chegar; (2) A catedral está perto da faculdade, portanto é fácil chegar; (3) Meu 
dormitório está perto do teu, portanto é fácil chegar. Esse fenômeno acontece, notadamente, em virtude das inúmeras formas de expressão que a língua permite realizar.

Além disso, mostram os referidos semanticistas (2005) que é o chamado quadrado argumentativo que formaliza o bloco semântico - entidade indecomponível subjacente aos encadeamentos e aspectos argumentativos. Para exemplificar, fazem intervir a noção de tempo (cronos), diferenciando um tempo-que-leva, que destrói as coisas e as faz desaparecer, de um tempo-que-traz, que cria as coisas e mostra presença.

Nessa direção, com os segmentos A (é tarde) e B (estar no escritório), ligados pelos conectores DC e PT e por NEG (negação), podem-se constituir oito aspectos argumentativos, cujo fenômeno revela a possibilidade de haver um bloco semântico 1 (BS1) do tempo-que-trazas-coisas e de um bloco semântico 2 (BS2), também de quatro aspectos, do tempo-que-leva-as-coisas. Notese, a seguir, que este é contrário àquele; e, já que os blocos semânticos podem ser esquematizados por meio de quadrados argumentativos, conforme Carel e Ducrot (2005), utilizam-se - na representação do BS1 e do BS2 quadrados argumentativos, cujos aspectos são numerados de (1) a (4) e de (1') a (4'). Confiram-se:

\begin{tabular}{|c|c|}
\hline $\begin{array}{l}\text { (1) A PT NEG-B } \\
\text { (1) TARDE PT NEG-ESTAR ESCRITÓRIO }\end{array}$ & $\begin{array}{l}\text { (2) NEG-A PT B } \\
\text { (2) NEG-TARDE PT ESTAR ESCRITÓRIO }\end{array}$ \\
\hline $\begin{array}{l}\text { (3) NEG-A DC NEG-B } \\
\text { (3) NEG-TARDE DC NEG-ESTAR ESCRITÓRIO }\end{array}$ & $\begin{array}{l}\text { (4) A DC B } \\
\text { (4) TARDE DC ESTAR ESCRITÓRIO }\end{array}$ \\
\hline
\end{tabular}

Figura 1. BS do tempo-que-traz (1): relaciona (A) tarde e (B) estar no escritório

Fonte: Figura fundamentada em Carel e Ducrot (2005, p. 34).

Nesse quadrado argumentativo - que formaliza o bloco semântico 1 (BS1), segundo o qual, quando se é tarde, se está no escritório [(A) tarde e (B) estar no escritório] - pode-se perceber que A é favorável a B. Portanto, o chamado tempo-que-traz é favorável à presença das coisas. A seguir, pode-se verificar o bloco contrário a este último:

(1) A PT B
(1) TARDE PT ESTAR ESCRITÓRIO
$\begin{array}{ll}\text { (3) NEG-A DC B } & \text { (2) NEG-A PT NEG-B } \\ \text { (3) NEG-TARDE DC ESTAR ESCRITÓRIO } & \text { (4) AARDE DC NEG-ESTAR ESCRITÓRIO }\end{array}$

Figura 2. $\mathrm{BS}$ do tempo-que-leva (2): relaciona (A) tarde e (B) não estar no escritório

Fonte: Figura fundamentada em Carel e Ducrot (2005, p. 35).

Relativamente a esse segundo bloco semântico (BS2), note-se que A é desfavorável a B, isto é, o tempo- que-leva é desfavorável à presença das coisas. Além disso, é importante ressaltar, tanto em relação ao BS1, quanto ao BS2 que as relações semânticas neles explicitadas não são de ordem lógica, uma vez que, diferentemente do quadrado aristotélico - que se encontra na ordem do pensamento, da lógica - o quadrado proposto pela TBS não faz intervir as noções de verdade. Saindo dos domínios da lógica, o quadrado argumentativo representa, como referido anteriormente, as relações entre quatro aspectos de um mesmo bloco semântico. A relação que se estabelece entre os aspectos transgressivos (1) e (2) e entre os normativos (3) e (4) é a mesma - denominada de reciprocidade -, a qual consiste em negar os termos que se encontram de um lado e de outro do conector, sem modificá-lo.

Na diagonal do quadrado, apresenta-se uma relação, cujo primeiro termo se conserva, mas troca-se o conector. Por exemplo, de PT (mesmo assim), em (1), passa-se para DC (portanto) em (4). Da mesma forma, de PT, em (2), passa-se para DC em (3). Essa relação é denominada por Carel e Ducrot (2005) de conversão. E, além dessas duas, outra relação do quadrado, que se estabelece entre (1) e (3) e entre (2) e (4), é a transposição, a propósito da qual vale referir que, quando se passa de (1) a (3), e igualmente de (2) a (4), nega-se o primeiro termo, troca-se o conector e mantém-se o segundo termo.

Feitos esses esclarecimentos sobre as relações formais e discursivas existentes nos quatro ângulos do quadrado argumentativo, apresentam-se, aqui, noções sobre argumentação interna (AI, daqui em diante) e sobre argumentação externa (AE, daqui em diante), essenciais às análises do corpus deste trabalho. A propósito da $\mathrm{AE}$, saliente-se que a própria entidade forma parte dos encadeamentos externos que a descrevem, e os aspectos pertencentes à AE existem sempre em pares. Sendo assim, se houver, na AE de prudente, por exemplo, o aspecto PRUDENTE DC SEGURANÇA, existirá, também, o aspecto PRUDENTE PT NEG-SEGURANÇA. Além disso, é importante ressaltar que a AE também pode ocorrer à direita e à esquerda. $\mathrm{A} \mathrm{AE}$ à direita de uma entidade $(e)$ é do tipo $e$ CON X, como PRUDENTE DC SEGURANÇA, e a AE à esquerda é do tipo X $\mathrm{CON} e$, por exemplo TEM MEDO DC É PRUDENTE e NEG-TEM MEDO PT É PRUDENTE.

Do mesmo modo, revisando-se o vínculo interno que há entre enunciados e entidades semânticas, verifica-se, conforme palavras de Carel e Ducrot (2005, p. 65), que a primeira característica da argumentação interna de uma $e$ é o fato de ela ser constituída por um certo número de aspectos aos quais pertencem os encadeamentos que a parafraseiam. Por conseguinte, duas características básicas são explicitadas pelos referidos linguistas para diferenciar uma AI de uma AE. A primeira é que os encadeamentos 
que formam parte da AI de $e$ não contêm $e$. Por exemplo, a AI de prudente é PERIGO DC PRECAUÇÃO; de temeroso, NEG-PERIGO PT PRECAUÇÃO; e de inteligente, NEG-FÁCIL PT COMPREENDE. E a segunda característica é que, na $\mathrm{AI}$ de uma entidade, não se encontram dois aspectos conversos, visto que a relação de conversão diz respeito unicamente à $\mathrm{AE}$.

Feitas essas considerações sobre os fundamentos filosóficos da ADL e sobre conceitos e princípios da fase atual da Semântica Argumentativa, apresentamse, na próxima seção, as contribuições que a ideologia da certeza pode apresentar na educação matemática, sobretudo se aliada aos princípios e conceitos da ADL/ TBS, conforme se pode verificar no presente trabalho.

\section{A ideologia da certeza na edução matemática}

É recorrente, em sociedade, o uso de números como forma de contribuir com a veracidade, a verossimilhança, ou seja, com o embasamento de informações que são apresentadas nas mais diversas situações de comunicação. Desse modo, dentre outros gêneros discursivos, a linguagem matemática é utilizada em anúncios publicitários, cartazes, contas de água, luz, telefone, discursos políticos, e muitas vezes é empregada estrategicamente como um recurso de defesa e até de imposição de um determinado ponto de vista.

Borba e Skovsmose (1997) observam que a matemática serve de suporte tanto para argumentações e debates acerca de questões sociais, quanto para a tomada de decisões de interesse coletivo. De acordo com os referidos autores (1997, p. 17), a matemática "se torna parte da linguagem com a qual sugestões políticas, tecnológicas e administrativas são apresentadas. A matemática torna-se parte da linguagem de poder".

Dado o grande número de informações a que as pessoas expõem-se diariamente - em muitas das quais a linguagem matemática também se faz presente - a demanda por conhecimentos matemáticos é imprescindível, especialmente para quando se pretende verificar quão válidas e aceitáveis podem ser essas informações. É importante observar, nesse momento, que os sujeitos com conhecimentos reduzidos no assunto tendem a dar crédito com mais facilidade a argumentos persuasivos. Sendo assim, a limitação de conhecimentos matemáticos inviabiliza o exame cuidadoso de que se necessita para averiguar a veracidade das informações acessadas.

Uma consequência desse desconhecimento por parte de uma parcela significativa da sociedade é que a matemática acaba por ganhar o status - equivocado - de que os números estão acima de manipulações. Em outras palavras, "a matemática é frequentemente retratada como instrumento/estrutura estável e inquestionável em um mundo muito instável". (BORBA, SKOVSMOSE, 1997, p. 127).

Segundo Skovsmose (2013), a visão de que a matemática é infalível é reforçada por programas de televisão sobre ciências, pelas escolas e mesmo pelas universidades. Nesses ambientes,

Frases como 'foi provado matematicamente', 'os números expressam a verdade', 'os números falam por si mesmos', 'as equações mostram/asseguram que' são frequentemente usadas na mídia e nas escolas. Essas frases parecem reforçar uma visão da matemática como uma referência 'acima de tudo', como um 'juiz', que está acima dos seres humanos, como um artifício humano que pudesse controlar a imperfeição humana. (SKOVSMOSE, 2013, p. 129)

Os números, quando elevados ao pressuposto de que estão acima de qualquer suspeita, podem ser utilizados para validar informações ou fatos que não correspondam à realidade. Essa crença, que confere uma credibilidade - de certa forma incondicional - à matemática, é denominada por Skvsmose como ideologia da certeza. Nas palavras desse autor (2013, p. 127), "O poder de conter o argumento definitivo atribuído à matemática é amparado pelo que denominaremos uma ideologia da certeza".

De acordo com Borba e Skovsmose (1997), a base da ideologia da certeza pode ser resumida pelas seguintes ideias:

1. A matemática é perfeita, pura e geral, no sentido de que a verdade de uma declaração matemática não se fixa em nenhuma investigação empírica. A verdade matemática não pode ser influenciada por nenhum interesse social, político ou ideológico.

2. A matemática é relevante e confiável, porque pode ser aplicada a todos os tipos de problemas reais. A aplicação da matemática não tem limite, já que é sempre possível matematizar um problema. (p. 20).

Conforme afirma Skovsmose (2013, p. 129), a ideologia da certeza trata-se de uma estrutura geral e fundamental de interpretação para um grande número de questões e, assim, acabam por transformar a matemática em uma linguagem com caráter decisivo nas relações de poder. "Essa visão da matemática - como um sistema perfeito, como pura, como uma ferramenta infalível se bem usada - contribui para o controle político".

Em vista disso, decisões não podem ser tomadas sem a verificação cuidadosa da origem dos números em questão, ou seja, da maneira como se chegou a tais números, qual foi a metodologia utilizada para a obtenção dos valores, qual a sua credibilidade e o que eles realmente querem dizer na situação discursiva em que estão inseridos. Dessa 
forma, no decorrer deste trabalho, elucidam-se situações em que os números podem ser utilizados equivocada e/ou ideologicamente.

\section{Metodologia e análise do corpus}

Utilizando-se o método de análise próprio da ADL/ TBS, foram evocados, primeiramente, os encadeamentos argumentativos de um discurso que constitui o corpus desta pesquisa e, a partir deles, foram examinados os sentidos argumentativos e polifônicos da linguagem numérica (números) neles empregada. Posteriormente, verificou-se a influência da chamada "ideologia da certeza" na constituição dos sentidos desse discurso, haja vista que, como já esclarecera Ducrot (1990, p. 151), a língua não é ideológica, mas não sobrevive sem a ideologia. É, portanto, evidente que tanto um linguista quanto um matemático - a despeito de a ideologia não ser o seu principal objeto de estudo - podem fazer considerações em relação às crenças sociais, as quais constituem ideologias, em suas análises discursivas. Confiram-se, a seguir, o discurso e a análise:

\section{Quadro 1. Discurso}

Patrimônio de Manuela D’Ávila, do PCdoB, cresce $1200 \%$

MARCELO SPERANDIO

24/07/2014 - 07h30 - Atualizado em 30/07/2014 - 19h14

A deputada federal Manuela D'Ávila, do PCdoB do Rio Grande do Sul, enriqueceu - e muito. De 2010 para este ano, seu patrimônio aumentou $1200 \%$. Saltou de R\$ 14 mil para R\$ 184 mil. Destaque para a sua conta poupança no Banco do Brasil, que saiu dos $\mathrm{R} \$ 9$ mil e chegou aos $\mathrm{R} \$ 94$ mil em quatro anos.

Fonte: <http://epoca.globo.com/colunas-e-blogs/felipe-patury/noticia/ 2014/07/bpatrimonio-de-manuela-davilab-do-pcdob-cresce-1200.html> Acesso em: 20 mar. 2015.

Pode-se verificar que esse discurso, publicado em revista de ampla circulação no Brasil (Época), constituise pela relação entre linguagens verbal e numérica. Desse modo, os números empregados no título e no corpo do texto estão desempenhando as funções próprias de signo linguístico (palavra), cujo fato não deve surpreender, pois, como já explicitado na introdução, os números também estão na língua.

Feitas essas primeiras constatações, pode-se verificar, com base na ADL/TBS, que a argumentação expressa nesse discurso pode ser representada no encadeamento argumentativo normativo [aumentar $1200 \%$ do patrimônio em quatro anos, portanto ser político corrupto], cujo aspecto expresso pode ser representado por ENRIQUECER MUITO (1200\%) EM POUCO TEMPO DC SER CORRUPTO. Diante disso, percebe-se que esse aspecto argumentativo normativo estabelecido sintagmaticamente no discurso - constitui uma argumentação externa à esquerda (AE à esquerda) de CORRUPTO, a qual fica em evidência já no título.

Examinando-se esse discurso também sob o eixo paradigmático, é possível evocar o encadeamento argumentativo transgressivo [transcorrer pouco tempo, mesmo assim enriquecer muito], cujo aspecto nele expresso PASSAR POUCO TEMPO PT ENRIQUECER MUITO (1200\%) constitui uma argumentação interna (AI) de corrupção. Trata-se, esse, de um sentido discursivo possível de se atribuir à palavra corrupção, o qual corrobora a AE de corrupto.

Relativamente ao tempo empregado nesse discurso, pode-se notar que se trata do chamado tempo-que-traz, que mostra presença, visto que, quanto mais passar o tempo, mais corrupção vai-se cometer. Nessa relação linguisticamente estabelecida, o tempo é o responsável pelo aumento excessivo de falcatrua, pois, se num curto período de tempo pôde-se cometer muita corrupção, num longo período, dever-se-á cometê-la ainda muito mais.

Em realidade, na relação que o número1200 estabelece com os outros signos desse discurso, surge, nesse próprio ideograma, uma orientação argumentativa que conduz a um predicado como portanto é corrupta ou portanto faz falcatrua. Observando-se, entretanto, os sentidos polifônicos nele existentes, pode-se continuar, por exemplo, com o predicado mesmo assim não é corrupta. Vejam-se, no quadrado argumentativo a seguir, os sentidos argumentativos e polifônicos desse discurso, evocados, também, pelo ideograma 1200 :

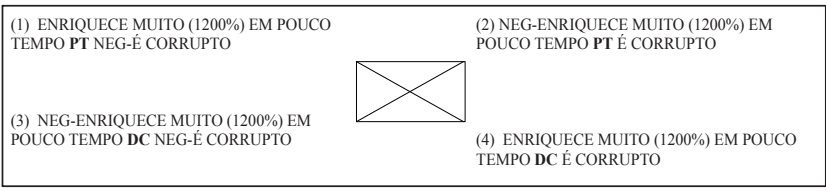

Figura 3. BS1: relaciona (A) enriquecer muito (1200\%) em pouco tempo e (B) ser corrupto

Fonte: Figura elaborada pelos autores.

Pode-se verificar que os quatro predicados $Y$ desse bloco semântico - a saber, (1) mesmo assim não é corrupto, (2) mesmo assim é corrupto, (3) portanto não é corrupto e (4) portanto é corrupto - existem implicitamente nesse discurso. Todos eles dialogam entre si, em virtude da própria polifonia inerente ao bloco semântico. Desse modo, ao empregar explicitamente, no discurso, os predicados X (1) e (4), enriquece muito (1200\%) em роисо tempo, o locutor também instaura virtualmente os predicados $X(2)$ e (3) e os quatro predicados $Y$ referidos anteriormente. Sendo assim, ao alocutário, resta posicionar-se frente a esses pontos de vista, sempre com o cuidado de não simplesmente concordar com aqueles pontos de vista expressos no aspecto argumentativo identificado pelo locutor - nesse caso, o norma- 
tivo (4) ENRIQUECE MUITO (1200\%) EM POUCO TEMPO DC É CORRUPTO.

Existe essa necessidade de o alocutário posicionar-se em relação aos pontos de vista a que lhe são atribuídos, justamente em virtude de a argumentação constituir-se, sempre, de uma apreensão subjetiva e intersubjetiva da realidade e de o próprio funcionamento da língua estar subordinado à ideologia presente na sociedade. Desse modo, a propósito da análise desse discurso, é fundamental observar que o número 1200 ocupa uma posição de advérbio de intensidade que, como muito, modifica o sentido do verbo crescer. Não bastasse sua posição sintática no enunciado, é preciso ressaltar que sua escolha fica absolutamente subordinada à ideologia concernente ao uso da matemática em sociedade, visto que a citação de um dado estatístico no discurso pode dar-lhe maior sensação de veracidade, podendo ganhar com mais facilidade - a credibilidade do alocutário.

Contudo, o que é interessante de também se observar nesse discurso é o fato de esse dado estatístico poder ser desvelado matemática e linguisticamente nele mesmo. Analisando-o de um ponto de vista matemático, e observando-se que o subsídio de um deputado estadual cargo atualmente ocupado pela política Manoela D'Ávila - é de R\$ 25.322,25 (cf. divulgado pela Assembleia Legislativa), pode-se realizar uma leitura divergente daquela a que conduz argumentativamente esse discurso.

Como expresso na reportagem veiculada pela revista Época, Manoela teve um aumento no patrimônio igual a 170 mil reais - de 14 mil para 184 mil reais - em 42 meses, de 2010 (data informada pela matéria) até junho de 2014 - visto que a matéria foi divulgada em julho do mesmo ano. O texto afirma, também, que parte desse valor, 94 mil reais, estava aplicado em uma poupança do Banco do Brasil e, quanto à outra parte - os outros R \$ 90 mil - não houve divulgação a respeito da forma de investimento.

Assim, neste trabalho, opta-se por considerar que o aumento do patrimônio deu-se a partir dos rendimentos, exclusivamente, da poupança, por três motivos. O primeiro é que, como já exposto, uma parte considerável do dinheiro foi aplicada nessa modalidade; o segundo é que, de acordo com o Serviço de Proteção ao Crédito SPC, apesar de ser um investimento menos lucrativo do que outras formas de investimento, a poupança é o mais popular entre os brasileiros; e o terceiro deu-se em virtude de a poupança, como afirmado pelo SPC, ser menos atrativa do que outras formas de investimento ofertadas pelo mercado - o que, de certa forma, torna a análise mais justa, uma vez que, se for possível a aquisição de determinado valor por meio de um rendimento menor, consequentemente, com um rendimento mais compensador, também o será.
Quanto ao rendimento da poupança, segundo o Banco Central do Brasil, a remuneração dos depósitos é composta por duas parcelas: a remuneração básica, dada pela Taxa Referencial, e a remuneração adicional. Esta corresponde a: (a) $0,5 \%$ ao mês, enquanto a meta da taxa Selic ao ano for superior a $8,5 \%$; ou (b) $70 \%$ da meta da taxa Selic ao ano, mensalizada, vigente na data de início do período de rendimento, enquanto a meta da taxa Selic ao ano for igual ou inferior a $8,5 \%$.

No período em questão, segundo o Banco Central do Brasil, a taxa Selic sempre foi superior a $8,5 \%$, ou seja, a chamada remuneração adicional no período permaneceu estável em $0,5 \%$ e a TR apresenta uma variação mensal. Como esse índice é flutuante, e tende a aumentar os rendimentos, ele será desconsiderado neste trabalho. Aqui, segue-se a mesma lógica de que, se for possível adquirir certa quantia sob juros menores, igualmente $o$ será sob juros maiores.

Frente a essas informações, calcula-se o valor que a parlamentar deveria ter aplicado mensalmente na poupança, no decorrer do período em questão, para, ao final dos 42 meses, obter o referido aumento no patrimônio. Para tanto, usa-se o sistema Price de amortização, que, segundo Poitras (2000), foi desenvolvido pelo matemática e físico Simon Stevin, nascido na Bélgica, no século XVI. Nesse sistema, as prestações/aplicações são iguais e periódicas, ou seja, as parcelas, denominadas PMT, possuem o mesmo valor e são divididas em $n$ intervalos iguais - normalmente mensais -, e $i$ representa a taxa de juros. $\mathrm{O}$ valor futuro, denominado $F V$, representa o valor que se deseja obter ao final das aplicações.

A fórmula que obtém o valor dos pagamentos mensais em função do tempo, taxa de juros, número de período e valor futuro é:

$$
P M T=\boldsymbol{F} \frac{i}{(1+i)^{n}-1}
$$

Figura 4. Fórmula do Sistema Price Fonte: Puccini (2009, p. 90)

Obter um aumento de 170 mil reais em 42 meses, em um cenário de rendimento da poupança de $0,5 \%$ ao mês, pode ser expresso, pela fórmula Price, atribuindo-se os seguintes valores às variáveis: $F V=170000,00, n=42$ e $i=0,5 \%$ ao mês; em contrapartida, a equação retorna o valor das aplicações mensais que deveriam ter sido realizadas pela deputada.

Desenvolvendo-se os cálculos, conclui-se que o valor a ser depositado mensalmente equivale a 3.647,56 reais, uma parcela referente a $14,4 \%$ do subsídio bruto da parlamentar, o que indica que o suposto "enriquecimento" - se é que assim se pode chamar o referido 
aumento no patrimônio - é absolutamente compatível com o salário em questão. Em outras palavras - e sem nenhum comprometimento ideológico dos autores deste trabalho - é preciso salientar que o real aumento no patrimônio da deputada não remete, em absoluto, à irregularidade, a ganho ilegal de dinheiro público, à falcatrua.

Em vista disso, destaque-se a importância de uma leitura cuidadosa dos dados matemáticos que constituem informações veiculadas em discursos. Neste caso, uma boa interpretação matemática pode transformar a orientação argumentativa contida no discurso de Época conforme se explicitou na análise, por meio da ADL/TBS, - de política corrupta, em boa gestora, cuja qualidade é fundamental a todo servidor público comprometido com sua função, especialmente a um servidor que, no uso de suas atribuições, tem de envolver-se em finanças públicas, como é o caso de um deputado estadual.

\section{Conclusão}

É de reconhecimento não só dos linguistas, mas também dos pesquisadores de educação matemática, que os números argumentam - sobretudo quando postos em relação com os signos linguísticos - em discursos. Apesar disso, como já afirmado inicialmente, ainda são escassos os trabalhos, em ambas as áreas, que busquem investigar esse elo semanticamente construído, cujos objetivos sejam, especificamente, explicitar a semântica da linguagem numérica nessa relação e desvelar os sentidos duvidosos e falsos de números em discursos.

Por esse motivo - adotando ferramentas de análise linguístico-discursiva postas à disposição pela Semântica Argumentativa, e assumindo posicionamentos relativos à ideologia da certeza na educação matemática - é nessa orientação que este trabalho se inscreve. Partiu-se, para esse fim, de uma análise argumentativa e polifônica de um discurso, cujos números nele empregados contêm orientações argumentativas que conduzem a continuações discursivas diferentes. Pôde-se perceber que a orientação argumentativa normativa contida em $1200 \%$ é PORTANTO É CORRUPTA, a partir da qual, pela polifonia do bloco semântico, também se pôde explicitar a orientação argumentativa transgressiva MESMO ASSIM NÃO É CORRUPTA. Desse modo, lendo-se matematicamente os números abaixo do título do discurso, verificou-se que - para ter existido desempenho qualificado em leitura do alocutário - teria sido necessário que ele assumisse esta continuação discursiva transgressiva, a qual está garantida linguisticamente, no próprio discurso.

Diante disso, pode-se afirmar que, assim como as palavras podem ser mal interpretadas em um discurso, os números igualmente podem sê-lo, haja vista que - ao entrarem em relação no sistema da língua - eles notadamente assumem as mesmas funções dos signos linguísticos. Além disso, não bastassem as suas múltiplas possibilidades de expressão - aritmética, probabilística etc - os números muitas vezes remetem a resultados desconhecidos às vistas do alocutário. Dessa maneira, para não precisarem de efetuar pesquisa em relação à sua confiabilidade, as pessoas geralmente acabam aceitando-os como verdadeiros, inclusive pelo grau de credibilidade instaurado, nas sociedades ocidentais, em relação às ciências "exatas", à matemática. Daí a afirmação de que, muitas vezes, os números devem ser menos confiáveis do que as próprias palavras.

Saliente-se, ainda, a necessidade de se continuar investigando os sentidos que os números adquirem em discursos, seus efeitos e suas consequências, quando da realização de leituras superficiais e equivocadas. Por fim, ressalte-se a necessidade de se levar para os ensino de língua e de ciências exatas - especialmente em disciplinas de matemática de nível médio e superior - as ferramentas teórico-metodológicas de leitura postas à disposição neste trabalho.

\section{Referências}

ANSCOMBRE, Jean-Claude; DUCROT, Oswald. L'Argumentation Dans la Langue. Bruxelles: Mardaga, 1983.

BANCO CENTRAL DO BRASIL. Remuneração dos Depósitos de Poupança. Disponível em: <https://www3.bcb.gov.br/ sgspub/consultarvalores/consultarValoresSeries.do?method= consultarValores >. Acesso em: 18 ago. 2015.

BANCO CENTRAL DO BRASIL. Remuneração dos Depósitos de Poupança. Disponível em: <http://www4.bcb.gov.br/pec/ poupanca/poupanca.asp>. Acesso em: 18 ago. 2015.

BARBISAN, Leci Borges. Semântica Argumentativa. In: JUNIOR, C. F.; BASSO, R. (Orgs.). Semântica, semânticas: uma introdução. 1. ed. São Paulo: Contexto, 2013. p. 19-30.

BECHARA, Evanildo. Moderna Gramática Portuguesa. 37. ed. Rio de Janeiro: Nova Fronteira, 2009.

BORBA, M. C.; SKOVSMOSE, O. The ideology of certainty. For the learning of Mathematics, v. 17, n. 3, p. 17-23, 1997.

CÂMARA JR., Joaquim Mattoso. Dicionário de lingüistica e gramática. 8. ed. Petrópolis: Vozes, 1978.

CAREL, Marion.Vers une formalisation de la Théorie de l'Argumentation dans la Langue. Thèse de Doctorat Nouveau Régime, EHESS, 1992.

CAREL, Marion; DUCROT, Oswald. La semántica argumentativa: una introducción a la teoría de los bloques semánticos. Tradução: María Marta Negroni e Alfredo M. Lescano. Buenos Aires: Colihue, 2005.

DUCROT, Oswald. Polifonía y Argumentación. Conferencias del Seminario Teoría de la Argumentación y Análisis del Discurso. Cali: Universidad del Valle, 1990. 
DUCROT, Oswald. La sémantique argumentative peut-elle se réclamer de Saussure? In: SAUSSURE, L. Nouveaux regards sur Saussure. Genebra: Librairie Droz, 2006.

DUCROT, Oswald. Prefácio. In: VOGT, C. O Intervalo Semântico: (contribuição para uma teoria semântica argumentativa). 2. ed. rev. São Paulo: Ateliê Editorial/Campinas: Editora da Unicamp, 2009. p. 9-19.

POITRAS, G. The early history of financial economic. 14781776. Cheltenham: Edward Elgar, 2000.

PUCCINI, A. L. Matemática financeira objetiva e aplicada. 8. ed. São Paulo: Saraiva, 2009.

SAUSSURE, Ferdinand de. Curso de Linguística Geral. Organizado por Charles Bally e Albert Sechehaye. Tradução de Antônio Chelini, José Paulo Paes e Izidoro Blikstein. 7. ed. São Paulo: Cultrix, 1975.

SAUSSURE, Ferdinand de. Escritos de linguística geral. BOUQUET, Simon; ENGLER, Rudolf (orgs.); WEIL,
Antoinette (Col.). Tradução Carlos Augusto Leuba Salum e Ana Lucia Franco. São Paulo: Cultrix, 2012. 296p.

SAVIOLI, Francisco Platão; FIORIN, José Luiz. Lições de texto: leitura e redação. 4. ed. São Paulo: Ática, 1999.

SERVIÇO DE PROTEÇÃO AO CRÉDITO. $65 \%$ dos brasileiros que investem na poupança buscam se sentir seguros. Disponível em: <https://www.spcbrasil.org.br/imprensa/noticia/65165dos brasileirosqueinvestemnapoupancabuscamsesentirseguros dizspcbrasil>. Acesso em: 23 ago. 2015.

SKOVSMOSE, O. Educação matemática crítica: a questão da cidadania. 6. ed. São Paulo: Papirus, 2013.

Recebido: 25 de agosto de 2015.

Aprovado: 20 de novembro de 2015.

Contato: lauro.20@bol.com.br norton.manassi@erechim.ifrs.edu.br noemi.santos@erechim.ifrs.edu.br 